\title{
Effects of 5-aza-2' deoxycytidine on RECK gene expression and tumor invasion in salivary adenoid cystic carcinoma
}

\author{
X.Q. Zhou ${ }^{1,2,3 *}$, S.Y. Huang ${ }^{3 *}$, D.S. Zhang ${ }^{1,3 *}$, S.Z. Zhang ${ }^{3}$, W.G. Li ${ }^{3}$, Z.W. Chen ${ }^{3}$ and H.W. Wu ${ }^{3}$ \\ ${ }^{1}$ Department of Oral and Maxillofacial Surgery, School of Stomatology, Shandong University, Jinan, China \\ ${ }^{2}$ Department of Oral and Maxillofacial Surgery, The First People's Hospital of Jining, Shandong, China \\ ${ }^{3}$ Department of Oral and Maxillofacial Surgery, Shandong Provincial Hospital, Affiliated to Shandong University, Jinan, China
}

\begin{abstract}
Reversion-inducing cysteine-rich protein with kazal motifs (RECK), a novel tumor suppressor gene that negatively regulates matrix metalloproteinases (MMPs), is expressed in various normal human tissues but downregulated in several types of human tumors. The molecular mechanism for this downregulation and its biological significance in salivary adenoid cystic carcinoma (SACC) are unclear. In the present study, we investigated the effects of a DNA methyltransferase (DNMT) inhibitor, 5-aza$2^{\prime}$ deoxycytidine (5-aza-dC), on the methylation status of the RECK gene and tumor invasion in SACC cell lines. Methylationspecific PCR (MSP), Western blot analysis, and quantitative real-time PCR were used to investigate the methylation status of the RECK gene and expression of RECK mRNA and protein in SACC cell lines. The invasive ability of SACC cells was examined by the Transwell migration assay. Promoter methylation was only found in the ACC-M cell line. Treatment of ACC-M cells with 5-aza-dC partially reversed the hypermethylation status of the RECK gene and significantly enhanced the expression of mRNA and protein, and 5-aza-dC significantly suppressed ACC-M cell invasive ability. Our findings showed that 5-aza-dC inhibited cancer cell invasion through the reversal of RECK gene hypermethylation, which might be a promising chemotherapy approach in SACC treatment.
\end{abstract}

Key words: RECK; Salivary adenoid cystic carcinoma; 5-aza-2'deoxycytidine; Methylation; Transwell assay

\section{Introduction}

Salivary adenoid cystic carcinoma (SACC) is one of the most common subtypes of malignant tumors. It accounts for only $1 \%$ of all head and neck malignancies, but it is well known for both distant metastasis and perineural invasion $(1,2)$. Despite aggressive surgery, long-term survival is only $39.6 \%$ after 15 years (3). The underlying molecular mechanisms of carcinogenesis are still unclear.

The reversion-inducing cysteine-rich protein with kazal motifs (RECK) gene was identified by screening an expression library for cDNAs that could reverse the round morphology associated with v-Ki-ras-transformation of 3T3 cells to the nontransformed flat morphology (4). It is thought to be a novel matrix metalloproteinase (MMP) inhibitor that can inhibit tumor angiogenesis, invasion, and metastasis. RECK is expressed in various normal human tissues, but downregulated in several types of human cancers, including pancreatic (5), colorectal (6), breast (7), and hepatocellular carcinoma (8). In a previous study (9), we found that RECK expression was significantly lower in SACC than in normal tissues, but the mechanism was not clear.

DNA methylation changes are frequently found in human cancers $(10,11)$. Hypomethylation of oncogenes can result in aberrant activation, and hypermethylation of suppressor genes can lead to silencing. Several methylation-regulated candidate genes have been identified in SACC, including auprabasin (SBSN) (12), aquaporin 1 (AQP1) (13), phosphatase and tensin homolog deleted on chromosome 10 (PTEN) (14), cyclin-dependent kinase inhibitors (15), RASassociated domain family protein 1A (RASSF1) (16), and death-associated protein kinase (DAPK) (17), but the methylation of RECK in SACC has not yet been reported.

In the present study, we examined the methylation status of the RECK gene and determined the effects of 5aza-2'deoxycytidine (5-aza-dC) treatment on its methylation status and expression level in human adenoid cystic carcinoma cell lines. The overall aim was the development

Correspondence: Dong-sheng Zhang: <ds63zhang@sdu.edu.cn>.

${ }^{*}$ These authors contributed equally to this study.

Received May 2, 2014. Accepted October 13, 2014. First published online December 12, 2014. 
of new strategies for cancer prevention and therapeutic interventions.

\section{Material and Methods}

\section{Cell lines and cell cultures}

Two human salivary adenoid cystic carcinoma cell lines, ACC-2 and ACC-M, were used. Both cell lines were kindly provided by Professor Wantao Chen (Department of Oral and Maxillofacial Surgery, Ninth People's Hospital, College of Stomatology, Shanghai Jiao Tong University, Shanghai, China). The cells were cultured in Dulbecco's modified Eagle's medium (DMEM) with 10\% fetal bovine serum (FBS; Hyclone, USA) and antibiotics in a humidified $37^{\circ} \mathrm{C}$ incubator containing $5 \% \mathrm{CO}_{2}$.

\section{Cell viability assay}

Briefly, cells were seeded on 96-well plates and treated with 5-aza-dC in triplicate. After 24,72 , or 144 h incubation, the medium was replaced with fresh medium containing $0.5 \mathrm{mg} / \mathrm{mL}$ 3-(4,5-dimethylthiazol-2-yl)-2,5-diphenyltetrazolium bromide (MTT). After $4 \mathrm{~h}$, the supernatants were removed and the resulting MTT formazan was solubilized in DMSO and measured spectrophotometrically at $570 \mathrm{~nm}$.

\section{5-aza-dC treatment}

We treated the SACC cell lines in triplicate with 5-azadC (Sigma, USA) to determine dose- and time-dependent changes as described previously (18). Briefly cells were diluted to a low density $\left(5 \times 10^{5} / 100 \mathrm{~mm}\right.$ dish) $24 \mathrm{~h}$ before 5 -aza-dC treatment. Stock solutions of 5-aza-dC were dissolved in DMSO. Cells were treated with 1,5 , and $10 \mu \mathrm{M}$ 5-aza-dC for $144 \mathrm{~h}$, or $10 \mu \mathrm{M}$ 5-aza-dC for 24, 72, or $144 \mathrm{~h}$. Baseline expression was established in mock treatment of cells with the same volume of DMSO in triplicate.

\section{Bisulfite modification and methylation-specific PCR (MSP)}

Genomic DNA was isolated and modified using the CpGenome $^{\mathrm{TM}}$ Direct Prep Bisulfite Modification kit (Millipore, USA) according to the manufacturer's instructions. MSP reactions were performed using $2 \times$ Taq PCR MasterMix (Tiangen, China) in $25 \mathrm{~mL}$ volumes under the following conditions: $94^{\circ} \mathrm{C}$ for $3 \mathrm{~min}$, then 30 cycles at $94^{\circ} \mathrm{C}$ for $30 \mathrm{~s}$, $55^{\circ} \mathrm{C}$ for $30 \mathrm{~s}, 72^{\circ} \mathrm{C}$ for $60 \mathrm{~s}$, and $5 \mathrm{~min}$ at $72^{\circ} \mathrm{C}$. The PCR product lengths for methylated and unmethylated RECK are 195 and 199 bp. Universal Methylated DNA (Millipore) and normal human blood DNA were used as positive controls for the methylated and unmethylated conditions. Water blanks were used as a negative control. Positive and negative controls were used in each round of MSP. All assays were performed in triplicate. For each DNA sample, primer sets for methylated (M) and unmethylated (U) DNA were used for analysis (Table 1). The PCR products were separated on $2 \%$ agarose gels and visualized by ethidium bromide staining.
Table 1. RECK primer sequences for methylation-specific PCR.

\begin{tabular}{cc}
\hline RECK gene & \multicolumn{1}{c}{ Primer } \\
\hline Methylated & \\
Forward & 5'-ATAAAGAGTTTTGGTACGGGGTAC-3' \\
Reverse & 5'-AAA ACCGCGAAATACTCGAA-3' \\
Unmethylated & \\
Forward & 5'-TAAAGAGTTTTGGTATGGGGTATGT-3' \\
Reverse & 5'-CTCCAAACCACAAAATACTCAAA-3' \\
\hline
\end{tabular}

\section{RNA extraction and quantitative real-time PCR}

Total RNA was isolated from cultured cells using a Trizol reagent kit (TaKaRa, China) according to the manufacturer's protocol. The quantity and quality of the RNA samples were measured by spectrophotometry and electrophoresis. cDNA was synthesized from $1 \mu \mathrm{g}$ of total RNA using PrimeScript ${ }^{\mathrm{TM}}$ RT reagent kits with gDNA Eraser (TaKaRa). Quantitative real-time PCR reactions were performed using SYBR ${ }^{\circledR}$ Premix Ex Taq ${ }^{\mathrm{TM}}$ (TaKaRa) in $20 \mathrm{~mL}$ volumes under the following conditions: $95^{\circ} \mathrm{C}$ for $30 \mathrm{~s}$, followed by 40 cycles of $95^{\circ} \mathrm{C}$ for $5 \mathrm{~s}$ and $60^{\circ} \mathrm{C}$ for $20 \mathrm{~s}$. Glyceraldehyde-3phosphate dehydrogenase (GAPDH) was used as an internal control to check the efficiency of cDNA synthesis and PCR amplification. The RECK and GAPDH primers are shown in Table 2 . The $2^{-\Delta \Delta C T}$ method was used for analysis of quantitative real-time PCR data, and $\Delta \Delta C_{\mathrm{T}}$ (threshold cycle $)=\left(C_{\mathrm{T}}\right.$ RECK, treated group $-C_{\mathrm{T}} \mathrm{GAPDH}$, treated group $)-\left(C_{\mathrm{T}} R E C K\right.$ gene, untreated group $-C_{\mathrm{T}} \mathrm{GAPDH}$, untreated group). The change in RECK mRNA expression was calculated as $2^{-\Delta \Delta C T}$. All reactions were performed in triplicate with water controls.

\section{Western blot analysis}

Total cellular proteins were extracted, and were separated by $10 \%$ sodium dodecyl sulfate polyacrylamide gel electrophoresis (SDS-PAGE) as described previously (19). Proteins were transferred from gels to polyvinylidene fluoride membranes followed by incubation with the primary anti-RECK and anti-GAPDH antibodies. GAPDH was used as a loading control on each membrane. Enhanced chemiluminescence reagents were used to detect the proteins on the membranes. Anti-RECK antibody was purchased from Abcam (USA, at 1:1000 dilution) and anti-GAPDH antibody

Table 2. Primer sequences for quantitative real-time PCR.

\begin{tabular}{lc}
\hline Gene & Primer \\
\hline RECK & \\
Forward & 5'-TGCAAGCAGGCATCTTCAAA-3' \\
Reverse & 5'-ACCGAGCCCATTTCATTTCTG-3' \\
GAPDH & \\
Forward & 5'-GCAGGGGGGAGCCAAAAGGG-3' \\
Reverse & 5'-TGCCAGCCCCAGCGTCAAAG-3' \\
\hline
\end{tabular}




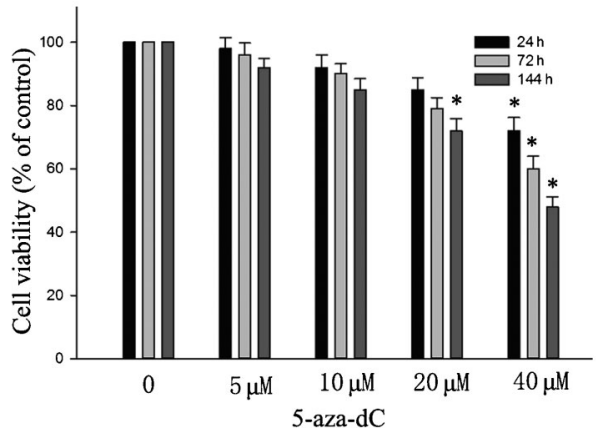

Figure 1. Effect of 5-aza-2' deoxycytidine (5-aza-dC) on viability of ACC-M cells. Cells were treated with various concentrations of 5 -aza-dC for 24,72 , and $144 \mathrm{~h}$. Cell viability is reported as means \pm SD of 3 independent experiments. ${ }^{*} P<0.05$ compared with control (ANOVA).

was obtained from Santa Cruz Biotechnology (USA, at 1:2500 dilution).

\section{In vitro invasion assay}

The invasiveness of cells exposed to 5 -aza-dC was assayed using Matrigel (BD, USA) coated $8 \mathrm{~mm}$ pore size filter inserts in 24-well plates (Sigma-Aldrich, USA). Cells exposed to 5-aza-dC $(1,5,10 \mu \mathrm{M})$ or DMSO for $72 \mathrm{~h}$ were collected and $1 \times 10^{5}$ cells in $200 \mu \mathrm{L}$ of medium were placed in the upper part of the Transwell unit and allowed to invade for $24 \mathrm{~h}$. The lower part of the Transwell unit was filled with $500 \mu \mathrm{L}$ medium containing 10\% FBS. After incubation, noninvasive cells on the upper part of the membrane were removed with a cotton swab. Invasive cells on the bottom surface of the membrane were fixed in formaldehyde for $20 \mathrm{~min}$, stained with crystal violet for $5 \mathrm{~min}$, and observed by light microscopy at $100 \times$ magnification. The number of cells in 5 randomly selected fields were counted; all assays were performed in triplicate.

\section{Statistical analysis}

SPSS (Statistic Package for Social Sciences) 13.0 for Windows (SPSS Inc., USA) was used to analyze data. Differences between groups were assessed by ANOVA with Dunnett's post hoc test. Statistical significance was defined as $\mathrm{P}<0.05$.

\section{Results}

\section{Cytotoxic effect of 5-aza-dC in ACC-M cells}

The cytotoxic effect of 5 -aza-dC in human adenoid cystic carcinoma ACC-M cells is shown in Figure 1. It is demonstrated that treatment with $40 \mu \mathrm{M}$ for $24 \mathrm{~h}$, or $20 \mu \mathrm{M}$ 5-aza-dC for $144 \mathrm{~h}$ significantly decreased the viability of ACC-M cells. Treatment with 5-aza-dC at doses of $10 \mu \mathrm{M}$ or less for $144 \mathrm{~h}$ did not cause cytotoxicity of ACC-M cells.

\section{Methylation status of RECK gene in ACC-2 and ACC-M cell lines}

MSP assays showed that the ACC-M cell lines contained both unmethylated and methylated promoters, but that ACC-2 had only a strongly unmethylated promoter (Figure 2A). Normal human blood DNA (NBD) was used as a positive control for unmethylated status and universal methylated DNA (UMD) as a positive control for methylated status, $\mathrm{H}_{2} \mathrm{O}$ was a negative control.

\section{Reversal of hypermethylation status in ACC-M cells by 5 -aza-dC}

The time- and dose-dependent effects of 5-aza-dC in ACC-M cell lines were investigated in cells treated with 1, 5, or $10 \mu \mathrm{M}$ of 5 -aza-dC for $144 \mathrm{~h}$. Methylation-specific RECK gene bands still existed but had a very weak appearance; however, the unmethylation-specific bands appeared to be enhanced. After treating the cells with $10 \mu \mathrm{M}$ of 5 -aza-dC for 24,72 , or $144 \mathrm{~h}$, unmethylation-specific bands of the $R E C K$ gene became increasingly intensive, and methylation-specific bands of the RECK gene became increasingly weaker (Figure 2B).

\section{5-aza-dC enhanced RECK mRNA and protein expression in ACC-M cell lines}

To confirm the effect of 5-aza-dC on expression of RECK mRNA, real-time quantitative PCR was performed in ACC-M cell lines after treatment with different concentrations of
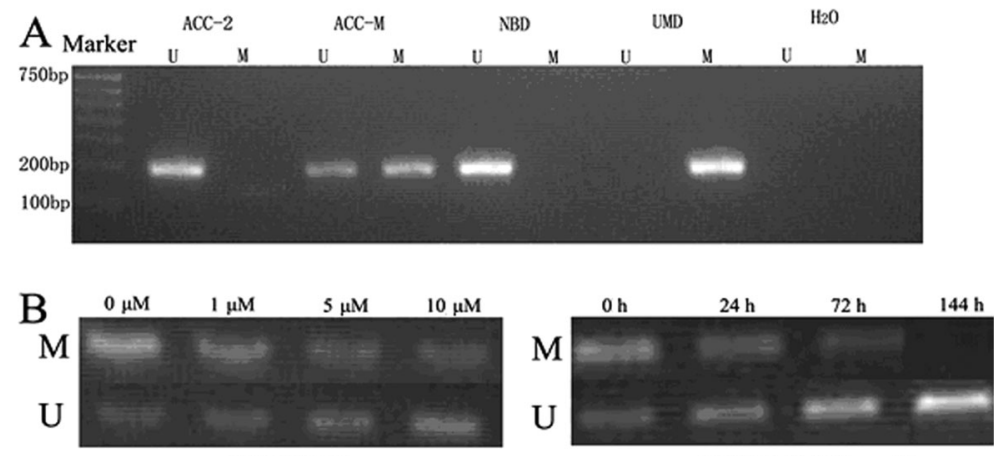

(ACC-M) 144 h

(ACC-M) $10 \mu \mathrm{M}$ 5-aza-dC
Figure 2. $A$, Methylation status of the RECK gene in ACC-2 and ACC-M cell lines. M: methylationspecific band; U: unmethylation-specific band; NBD: normal blood DNA as positive control for unmethylated status; UMD: universal methylated DNA as positive control for methylated status; $\mathrm{H}_{2} \mathrm{O}$ : negative control. $B$, Alterations of methylation status of the RECK gene in ACC-M cell lines after treatment with $1,5,10 \mu \mathrm{M}$ 5-aza-2'deoxycytidine (5-aza-dC) for $144 \mathrm{~h}$ and treated for 24 , 72 , and $144 \mathrm{~h}$ with $10 \mu \mathrm{M}$ 5-aza-dC. 

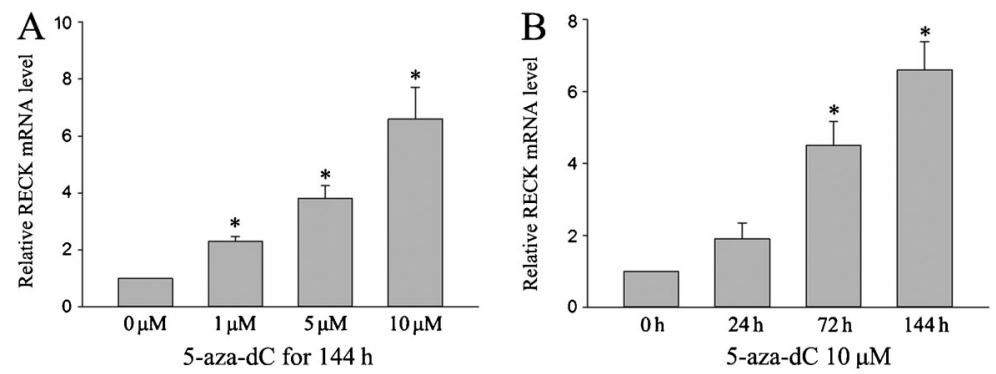

Figure 3. Relative mRNA expression levels of $R E C K$ gene by quantitative real-time PCR in ACC$M$ cell lines. 5-aza-2'deoxycytidine (5-aza-dC) enhanced RECK mRNA expression in a doseand time-dependent manner. All expression levels are shown relative to the untreated sample. Data are reported as means $\pm S D(n=3)$. ${ }^{*} P<0.05$ compared with control (ANOVA).

5-aza-dC for different times (Figure 3). The results showed that the relative amounts of RECK mRNA expressed increased in a dose- and time-dependent manner with significant effects at 1,5 , and $10 \mu \mathrm{M}(\mathrm{P}<0.05)$ and at 72 and $144 \mathrm{~h}(\mathrm{P}<0.05)$.

As shown in Figure 4, RECK protein expression was low in ACC-M cells. After treatment with different doses of 5-Aza-dC for $144 \mathrm{~h}$, or with $10 \mu \mathrm{M}$ of 5-Aza-dC for different times, RECK protein expression increased. These findings suggest that inhibition of RECK protein expression may be associated with RECK promoter methylation.

\section{DNA methyltransferase (DNMT) inhibitor 5-aza-dC} reduced the invasive ability of human ACC-M cells

As shown in Figure 5, treatment with 1, 5, or $10 \mu \mathrm{M}$ 5aza-dC significantly suppressed the invasive ability of ACC$M$ cells. We conclude that restoration of RECK expression by 5 -aza-dC is important for the inhibition of cell invasion by ACC-M cells.

\section{Discussion}

In the present study, we demonstrated that 5-aza-dC enhanced expression of RECK mRNA and protein by reversal of the hypermethylation status of the RECK promoter in a time- and dose-dependent manner, and could inhibit cancer cell invasion in ACC-M cell lines.

RECK is an important MMP inhibitor and is involved in the regulation of various physiological and pathological processes. Many studies have demonstrated that RECK
mRNA and protein are frequently highly expressed in both human tissue and untransformed cells, but are lost or not detectable in most tumor cells. Several hypotheses have been advanced to explain the mechanism of low RECK expression in tumor tissue. Epigenetic mechanisms have been shown to play an important role in the regulation of gene expression. Hsu et al. (20) reported that the oncogene HER-2/neu represses RECK by inducing the binding of Sp1 and Sp3 proteins as well as histone deacetylase (HDAC) to the Sp1-binding site. Sasahara et al. (21) reported that the HDAC inhibitor trichostatin A inhibited the interaction between HDAC and Sp1, which prevented binding to the Sp1 site, thereby restoring RECK expression.

DNA methylation of the RECK promoter and histone acetylation/deacetylation have been studied to uncover the underlying mechanisms of RECK expression (22). DNA methylation, a crucial epigenetic alteration, is associated with the silencing of tumor suppressor genes in several cancers. Cho et al. (23) found that downregulation of RECK mRNA and protein expression in colon tumor tissues significantly correlated with methylation of the RECK promoter. Chang et al. (24) suggested that downregulation of the metastasis suppressor RECK is caused by promoter methylation in non-small-cell lung cancer. In our previous research, we found RECK expression in SACC was significantly lower than in normal tissues, but the underlying mechanism by which RECK was downregulated in tumors has never been reported. In our present research, the methylation status of the RECK promoter assayed by MSP in ACC-M cell lines, characterized by frequent
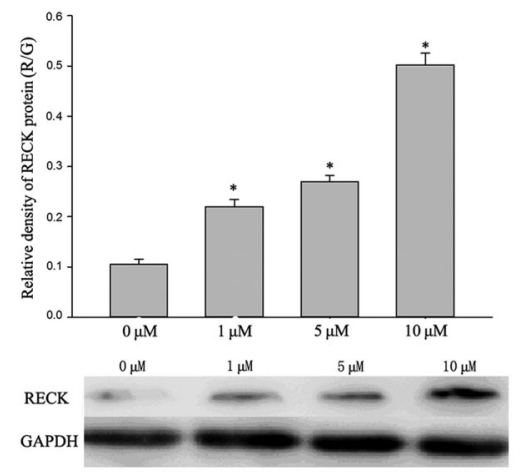

(ACC-X) $144 \mathrm{~h}$
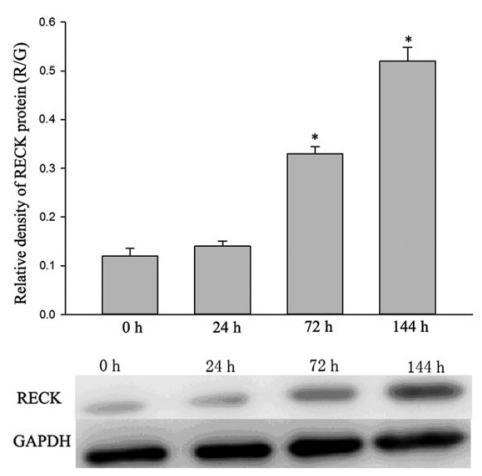

$(\mathrm{ACC}-\mathrm{M}) 10 \mu \mathrm{M}$

Figure 4. Western blotting results of RECK in ACC-M cells with DMSO or $1,5,10 \mu \mathrm{M}$ 5-aza2 'deoxycytidine (5-aza-dC) treatment for $144 \mathrm{~h}$ and treated for 24,72 , and $144 \mathrm{~h}$ with $10 \mu \mathrm{M} 5$ aza-dC. $R / G$ represents the brightness ratio of the RECK protein (106 kDa) vs GAPDH (36 kDa). ${ }^{*} \mathrm{P}<0.05$ compared with control (ANOVA). 

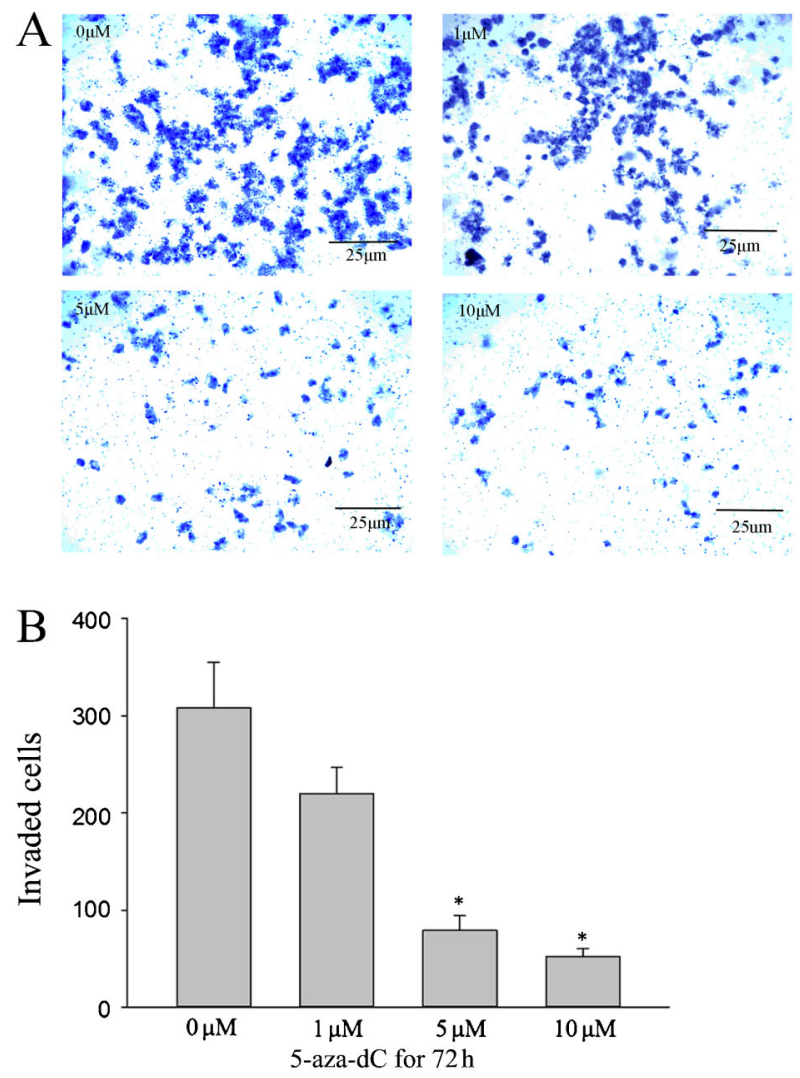

Figure 5. 5-aza-2'deoxycytidine (5-aza-dC) inhibited the invasion ability of ACC-M in a dose-dependent manner. Cells were incubated with DMSO or different doses of 5-aza-dC for $72 \mathrm{~h}$. After incubation for $24 \mathrm{~h}$, invaded cell numbers were counted as described previously $\left(100 \times\right.$ magnification). ${ }^{*} \mathrm{P}<0.05$ compared with control (ANOVA).

pulmonary metastasis and screened in ACC-2 cells, was both unmethylated and methylated, but ACC-2 had only unmethylated bands. The present study thus suggests that a decrease in or deficiency of RECK expression in ACC-M cells may be caused by the methylation of $\mathrm{CpG}$ islands in the RECK promoter region.

5 '-Azacytidine has been approved by the FDA for the treatment of myelodysplastic syndrome (25), which, as a classic DNMT inhibitor, was reported to restore RECK mRNA and protein expression by demethylation of the RECK promoter. Epigallocatechin-3-gallate (EGCG) is the major polyphenol and possibly the key active ingredient in green tea. Previous studies (26-29) have shown that EGCG inhibited DNMT and blocked the hypermethylation of newly synthesized DNA strands, resulting in the reversal of the hypermethylation and re-expression of silenced genes with reduced side effects and toxicity. This study demonstrated that almost no RECK protein was expressed in ACC-M cells (isolated from advanced lung metastases), which are characterized by high pulmonary metastasis and are isolated from ACC-2 lines. After ACC-M cells were treated with 5-aza-dC, the expression of RECK mRNA and protein was increased in a dose- and time-dependent manner. The invasiveness of ACC-M cells was significantly reduced by 5 -aza-dC treatment.

Degradation of extracellular matrix (ECM) is an important step during cell invasion and is usually mediated by extracellular proteases, such as MMPs. The inhibition of MMP-2 is a potential means for the prevention of the metastasis of cancer cells $(30,31)$. RECK acts as an inhibitor of MMPs and can inhibit tumor angiogenesis, invasion and metastasis (32). The expression of RECK in SACC is lower than that in normal tissue counterparts, and in our previous research decreased RECK was correlated with a poor prognosis (9). Enhancement of RECK expression may suppress cancer cell invasion (33). In the present study, 5-aza-dC had a significant effect on the invasive capability of ACC-M that was associated with increasing expression of RECK.

The mitogen-activated protein kinase (MAPK) pathway is known to participate in various signaling cascades that play an important regulatory role in cell growth, apoptosis, differentiation, and metastasis (34). Inhibition of the MAPK pathway may potentially prevent angiogenesis, proliferation, invasion, and metastasis in a wide range of tumors $(35,36)$. Metastasis is also regulated by the phosphatidylinositide-3 kinase/protein kinase B (PI3K/Akt) signaling pathway, which is involved in many cellular processes, including survival, adhesion, and metastasis $(37,38)$. The inhibition of the MAPK and PI3K/Akt pathways may potentially prevent cancer cell proliferation, invasion, and metastasis. Yan (39) reported that tomatidine inhibits the invasion of A549 cells by reducing the expression of MMPs, and also inhibits extracellular signal-regulated (ERK) and Akt signaling pathways and nuclear factor kappa light-chain enhancer of activated B cells (NF- $\kappa B$ ) activity. Although the effect of 5-aza-dC on suppressing invasiveness in ACC-M cells was demonstrated, the signal pathway remains unclear. In future studies, we will investigate the signal pathway to better understand the metastasis of SACC.

In conclusion, our findings are the first to show that 5aza-dC can inhibit cancer cell invasion through reversal of RECK gene hypermethylation, which could serve as a promising chemotherapeutic strategy for SACC treatment. Additional studies are needed to find a more tolerable and effective drug, and to uncover the mechanism underlying RECK hypermethylation in SACC.

\section{Acknowledgments}

Research supported by the Natural Science Foundation of Shandong Province (\#ZR2012HQ022). 


\section{References}

1. Barrett AW, Speight PM. Perineural invasion in adenoid cystic carcinoma of the salivary glands: a valid prognostic indicator? Oral Oncol 2009; 45: 936-940, doi: 10.1016/j.oraloncology. 2009.07.001.

2. Spiro RH, Huvos AG, Strong EW. Adenoid cystic carcinoma of salivary origin. A clinicopathologic study of 242 cases. Am J Surg 1974; 128: 512-520, doi: 10.1016/0002-9610(74)90265-7.

3. Fordice J, Kershaw C, El-Naggar A, Goepfert H. Adenoid cystic carcinoma of the head and neck: predictors of morbidity and mortality. Arch Otolaryngol Head Neck Surg 1999; 125: 149-152, doi: 10.1001/archotol.125.2.149.

4. Takahashi C, Sheng Z, Horan TP, Kitayama H, Maki M, Hitomi $\mathrm{K}$, et al. Regulation of matrix metalloproteinase- 9 and inhibition of tumor invasion by the membrane-anchored glycoprotein RECK. Proc Natl Acad Sci U S A 1998; 95: 13221-13226, doi: 10.1073/pnas.95.22.13221.

5. Masui T, Doi R, Koshiba T, Fujimoto K, Tsuji S, Nakajima S, et al. RECK expression in pancreatic cancer: its correlation with lower invasiveness and better prognosis. Clin Cancer Res 2003; 9: 1779-1784.

6. Takemoto N, Tada M, Hida Y, Asano T, Cheng S, Kuramae T, et al. Low expression of reversion-inducing cysteine-rich protein with Kazal motifs (RECK) indicates a shorter survival after resection in patients with adenocarcinoma of the lung. Lung Cancer 2007; 58: 376-383, doi: 10.1016/j.lungcan.2007. 07.004.

7. Figueira RC, Gomes LR, Neto JS, Silva FC, Silva ID, Sogayar MC. Correlation between MMPs and their inhibitors in breast cancer tumor tissue specimens and in cell lines with different metastatic potential. BMC Cancer 2009; 9: 20, doi: 10.1186/1471-2407-9-20.

8. Zhang $\mathrm{C}$, Ling $\mathrm{Y}$, Zhang $\mathrm{C}, \mathrm{Xu} \mathrm{Y}$, Gao L, Li R, et al. The silencing of RECK gene is associated with promoter hypermethylation and poor survival in hepatocellular carcinoma. Int J Biol Sci 2012; 8: 451-458, doi: 10.7150/ijbs.4038.

9. Zhou X, Huang S, Jiang L, Zhang S, Li W, Chen Z, et al. Expression of RECK and MMP-2 in salivary adenoid cystic carcinoma: Correlation with tumor progression and patient prognosis. Oncol Lett 2014; 7: 1549-1555.

10. Ehrlich M. DNA hypomethylation in cancer cells. Epigenomics 2009; 1: 239-259, doi: 10.2217/epi.09.33.

11. Herman JG, Baylin SB. Gene silencing in cancer in association with promoter hypermethylation. N Engl J Med 2003; 349: 2042-2054, doi: 10.1056/NEJMra023075.

12. Shao C, Tan M, Bishop JA, Liu J, Bai W, Gaykalova DA, et al. Suprabasin is hypomethylated and associated with metastasis in salivary adenoid cystic carcinoma. PLoS One 2012; 7: e48582, doi: 10.1371/journal.pone.0048582.

13. Shao C, Sun W, Tan M, Glazer CA, Bhan S, Zhong X, et al. Integrated, genome-wide screening for hypomethylated oncogenes in salivary gland adenoid cystic carcinoma. Clin Cancer Res 2011; 17: 4320-4330, doi: 10.1158/1078-0432.CCR-102992.

14. Fan X, Chen B, Xu J, Zhang H, Deng F, Xiang X. Methylation status of the PTEN gene in adenoid cystic carcinoma cells. Mol Med Rep 2010; 3: 775-779.

15. Daa T, Kashima K, Kondo Y, Yada N, Suzuki M, Yokoyama S. Aberrant methylation in promoter regions of cyclin-dependent kinase inhibitor genes in adenoid cystic carcinoma of the salivary gland. APMIS 2008; 116: 21-26, doi: 10.1111/j.16000463.2008.00773.x.

16. Williams MD, Chakravarti N, Kies MS, Maruya S, Myers JN, Haviland JC, et al. Implications of methylation patterns of cancer genes in salivary gland tumors. Clin Cancer Res 2006; 12: 7353-7358, doi: 10.1158/1078-0432.CCR-06-1272.

17. Li J, El-Naggar A, Mao L. Promoter methylation of p16INK4a, RASSF1A, and DAPK is frequent in salivary adenoid cystic carcinoma. Cancer 2005; 104: 771-776, doi: 10.1002/cncr.21215.

18. Yamashita K, Upadhyay S, Osada M, Hoque MO, Xiao Y, Mori $\mathrm{M}$, et al. Pharmacologic unmasking of epigenetically silenced tumor suppressor genes in esophageal squamous cell carcinoma. Cancer Cell 2002; 2: 485-495, doi: 10.1016/ S1535-6108(02)00215-5.

19. Liu LT, Chang HC, Chiang LC, Hung WC. Histone deacetylase inhibitor up-regulates RECK to inhibit MMP-2 activation and cancer cell invasion. Cancer Res 2003; 63: 3069-3072.

20. Hsu MC, Chang HC, Hung WC. HER-2/neu represses the metastasis suppressor RECK via ERK and Sp transcription factors to promote cell invasion. J Biol Chem 2006; 281: 4718-4725, doi: 10.1074/jbc.M510937200.

21. Sasahara RM, Takahashi C, Noda M. Involvement of the Sp1 site in ras-mediated downregulation of the RECK metastasis suppressor gene. Biochem Biophys Res Commun 1999; 264: 668-675, doi: 10.1006/bbrc.1999.1552.

22. Sasahara RM, Brochado SM, Takahashi C, Oh J, MariaEngler SS, Granjeiro JM, et al. Transcriptional control of the RECK metastasis/angiogenesis suppressor gene. Cancer Detect Prev 2002; 26: 435-443, doi: 10.1016/S0361-090X(02) 00123-X.

23. Cho CY, Wang JH, Chang HC, Chang CK, Hung WC. Epigenetic inactivation of the metastasis suppressor RECK enhances invasion of human colon cancer cells. J Cell Physiol 2007; 213: 65-69, doi: 10.1002/jcp.21089.

24. Chang HC, Cho CY, Hung WC. Downregulation of RECK by promoter methylation correlates with lymph node metastasis in non-small cell lung cancer. Cancer Sci 2007; 98: 169173, doi: 10.1111/j.1349-7006.2006.00367.x.

25. Das PM, Singal R. DNA methylation and cancer. J Clin Oncol 2004; 22: 4632-4642, doi: 10.1200/JCO.2004.07.151.

26. Stresemann C, Brueckner B, Musch T, Stopper H, Lyko F. Functional diversity of DNA methyltransferase inhibitors in human cancer cell lines. Cancer Res 2006; 66: 2794-2800, doi: 10.1158/0008-5472.CAN-05-2821.

27. Hellebrekers DM, Griffioen AW, van Engeland M. Dual targeting of epigenetic therapy in cancer. Biochim Biophys Acta 2007; 1775: 76-91.

28. Shaw RJ, Hall GL, Lowe D, Bowers NL, Liloglou T, Field JK, et al. CpG island methylation phenotype (CIMP) in oral cancer: associated with a marked inflammatory response and less aggressive tumour biology. Oral Oncol 2007; 43: 878-886, doi: 10.1016/j.oraloncology.2006.10.006.

29. Kato K, Long NK, Makita H, Toida M, Yamashita T, Hatakeyama D, et al. Effects of green tea polyphenol on methylation status of RECK gene and cancer cell invasion in oral squamous cell carcinoma cells. Br J Cancer 2008; 99: 647-654, doi: 10.1038/sj.bjc.6604521. 
30. Bodey B, Bodey B Jr, Groger AM, Siegel SE, Kaiser HE. Invasion and metastasis: the expression and significance of matrix metalloproteinases in carcinomas of the lung. In Vivo 2001; 15: 175-180.

31. Hrabec E, Strek M, Nowak D, Greger J, Suwalski M, Hrabec Z. Activity of type IV collagenases (MMP-2 and MMP-9) in primary pulmonary carcinomas: a quantitative analysis. $J$ Cancer Res Clin Oncol 2002; 128: 197-204, doi: 10.1007| s00432-001-0320-3.

32. Clark JC, Thomas DM, Choong PF, Dass CR. RECK - a newly discovered inhibitor of metastasis with prognostic significance in multiple forms of cancer. Cancer Metastasis Rev 2007; 26: 675-683, doi: 10.1007/s10555-007-9093-8.

33. Rabien A, Ergun B, Erbersdobler A, Jung K, Stephan C. RECK overexpression decreases invasive potential in prostate cancer cells. Prostate 2012; 72: 948-954, doi: 10.1002 pros.21498.

34. Chan-Hui PY, Weaver R. Human mitogen-activated protein kinase kinase kinase mediates the stress-induced activation of mitogen-activated protein kinase cascades. Biochem $J$ 1998; 336 (Part 3): 599-609.
35. Chen PN, Hsieh YS, Chiou HL, Chu SC. Silibinin inhibits cell invasion through inactivation of both PI3K-Akt and MAPK signaling pathways. Chem Biol Interact 2005; 156: 141-150, doi: 10.1016/j.cbi.2005.08.005

36. Chien CS, Shen KH, Huang JS, Ko SC, Shih YW. Antimetastatic potential of fisetin involves inactivation of the PI3K/Akt and JNK signaling pathways with downregulation of MMP-2/9 expressions in prostate cancer PC-3 cells. Mol Cell Biochem 2010; 333: 169-180, doi: 10.1007/s11010-009-0217-z.

37. Kim D, Kim S, Koh H, Yoon SO, Chung AS, Cho KS, et al. Akt/PKB promotes cancer cell invasion via increased motility and metalloproteinase production. FASEB J 2001; 15: 19531962, doi: 10.1096/fj.01-0198com.

38. Shukla S, MacLennan GT, Hartman DJ, Fu P, Resnick MI, Gupta S. Activation of PI3K-Akt signaling pathway promotes prostate cancer cell invasion. Int J Cancer 2007; 121: 14241432, doi: 10.1002/ijc.22862.

39. Yan KH, Lee LM, Yan SH, Huang HC, Li CC, Lin HT, et al. Tomatidine inhibits invasion of human lung adenocarcinoma cell A549 by reducing matrix metalloproteinases expression. Chem Biol Interact 2013; 203: 580-587, doi: 10.1016/j.cbi.2013.03.016. 